\title{
Analysis of the Factors Affecting the Willingness of Rural Left-Behind Women to Take up Elderly Care Service Under the Capital of Livelihood
}

\section{- Taking Wugang City, Hunan Province as an Example}

\author{
Chunmei Liu ${ }^{1}$, Min Zhang ${ }^{1}$, Rongxin Xu ${ }^{1} \&$ Jiayu Pen ${ }^{1}$ \\ ${ }^{1}$ School of Economics and Management, Huizhou University, Huizhou, China \\ Correspondence: Chunmei Liu, School of Economics and Management, Huizhou University, Huizhou 516100, \\ Guangdong, China.
}

Received: November 10, 2018

Accepted: December 13, 2018 Online Published: December 28, 2018

doi:10.20849/abr.v3i3.530

URL: https://doi.org/10.20849/abr.v3i3.530

\begin{abstract}
With the development of China's elderly care industry, pension service institutions have become the main channel to provide effective care to the elderly. However, at present, that nursing staff hardly to be recruited, managed and retained has become a universal problem. This article mainly adopts the questionnaire survey method to investigate the left-behind women in Wugang city of Hunan province, and uses the Logistic regression model to analyze the factors of the left-behind women's willingness to elderly care service from five aspects: human capital, social capital, natural capital, material capital and financial capital. The results shows that human capital such as education level and skill training, material capital of housing value, and financial capital with deposit have a significant impact on their choices.
\end{abstract}

Keywords: livelihood capital, rural left-behind women, elderly care service, willingness

With the rapid aging and the development of the elderly service industry, pension agencies have become the main channel to solve the problem of elderly care service. However, at present, that nursing staff hardly to be recruited, managed and retained has become a universal problem. According to the data from Chinese academy of social management, the number of semi-disabled and disabled elderly will reach 74.52 to 82.64 million by 2020 , and the number of elderly care staff should reach 6.57 to 7.31 million, there is a 3 to 5 million gap estimated between demand and supply .

On the other side, since the 1980s, a large number of rural surplus labor forces in China has been gradually transferred to cities and towns, the married women are left at home to take care of the family, who are called the rural left-behind women . Even by conservative estimates, this group has reached 47 million people, almost about 54 percent of the rural left-behind population, which is large and growing.

There is a phenomenon on a great shortage of elderly care staff and a large surplus of left-behind women. Can left-behind women make up for this gap? This paper investigates the left-behind women's willingness and the influencing factors to elderly service their willingness from the livelihood cost perspective.

\section{The Current Supply and Demand Situation of the Elderly Care Staff}

The elderly care staff are defined as people who take care of the elderly as the National Occupational Standards, mainly in the elderly agency and the community. According to a study by the China Institute of Social Management, the number of disabled and elderly people in China will reach 599-6.74 million by 2020, and the number of semi-disabled will reach 68.52-75.9 million. From that, we can extrapolate that the number of elderly care staff in China should reach 6.57-7.31 million. At present, there are only about 2 million staff in China. Meanwhile the latest estimate of the United Nations in 2010, under the assumption of a low fertility rate (that is, the fertility rate is below 2.1), the Chinese mainland's population of 15-64 years of working age will reach a peak of 989 million by 2020 . Obviously, the gap between demand and supply for elderly care staff is increasing. 


\section{Model Construction and Research Hypothesis}

\subsection{Theoretical Basis of Research}

Sustainable livelihood refers to the re-arrangement of the living capital that is owned by the choice of differentiated livelihood strategies in different situations to achieve sustainable use of live capital and sustained growth of family welfare. The UK's International Development Agency's Sustainable Livelihoods Analysis Framework provides a clear and concise overview of how vulnerable individuals and households can make diversified livelihood options under livelihood capital constraints to generate different livelihood outcomes and achieve sustainability through feedback on livelihood capital. In general, the more stocks of livelihood capital ,the greater the range of alternative livelihood strategies and the greater the ability to flexibly switch between strategies ,ultimately contributing to the achievement of livelihoods. This paper divides livelihood capital into five types: human capital, social capital, natural capital, physical capital and financial capital. From the perspective of livelihood costs, it discusses its impact on the willingness of rural left-behind women to engage in old-age services.

\subsection{Model Construction and Variable Design}

In this paper whether the rural left-behind women are willing to engage in the work of nursing care as a dependent variable, and use the phrase "If there is a career provided by the elderly care service, whether they are willing to choose", the answer is divided into "No" and "Yes". "No" is a reference class, which forms a typical binomial categorical variable. The logistic regression model is used to analyze the willingness of the remaining resources under the costs of livelihood to affect the left-behind women. The Specific linear form is :

$$
\ln [p /(1-p)]=g(x)=\beta_{0}+\sum \beta_{j} x_{j}
$$

In the formula (1), $\mathrm{j}=1,2, \ldots \ldots \ldots . . . \mathrm{m}, \mathrm{X}_{\mathrm{j}}$ represents the resources owned by rural left-behind women.

Combining the actual development of the aged care industry, human capital, social capital, natural capital, and physical capital will be broken down into the following specific indicators. Human resources are mainly analyzed for the education level of rural left-behind women, skills training, work experience in the second and third industries, and satisfaction with their own health. The degree of education is mainly divided from illiterate, elementary school, junior high school, high school and above. Skills training and work experience use"yes"and "no" as reference objects, and whether they are satisfied with their own health, the answer is based on Likert5,which is a continuous variable. Social capital is a continuous variable and an integer variable from the rural left-behind women, which is reflected in the number of people who need to borrow money, the number of people who are in difficulty in production, the number of people who can be taken care of when they are sick, and the number of people who can relax themselves. Natural capital is mainly reflected by the land area. Material capital is mainly reflected in the number of housing units and the value of housing .Financial capital is mainly reflected in whether it has been from bank loans in the past year and whether there are deposits under its own name. As for the rural left-behind women's views on the work of pension care, they are reflected mainly through the treatment and welfare of the old-age care work, the nature of the work, the social status, the contribution of meaning and the development prospects.

Table 1. Variable table

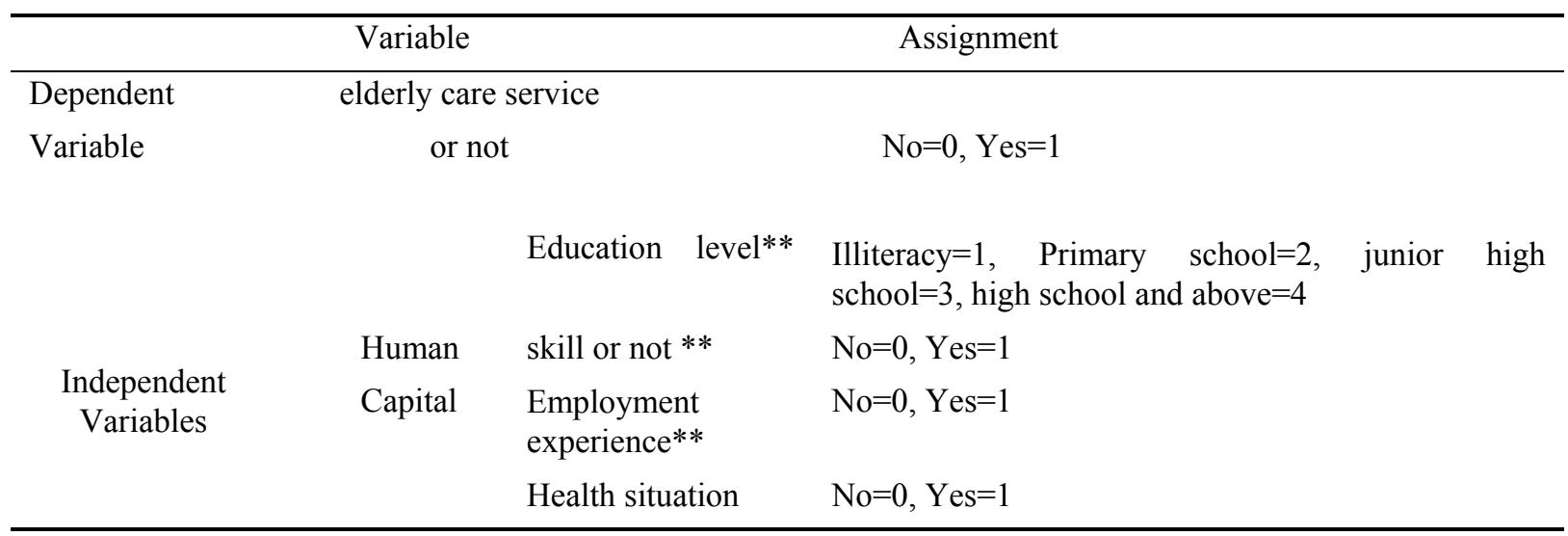




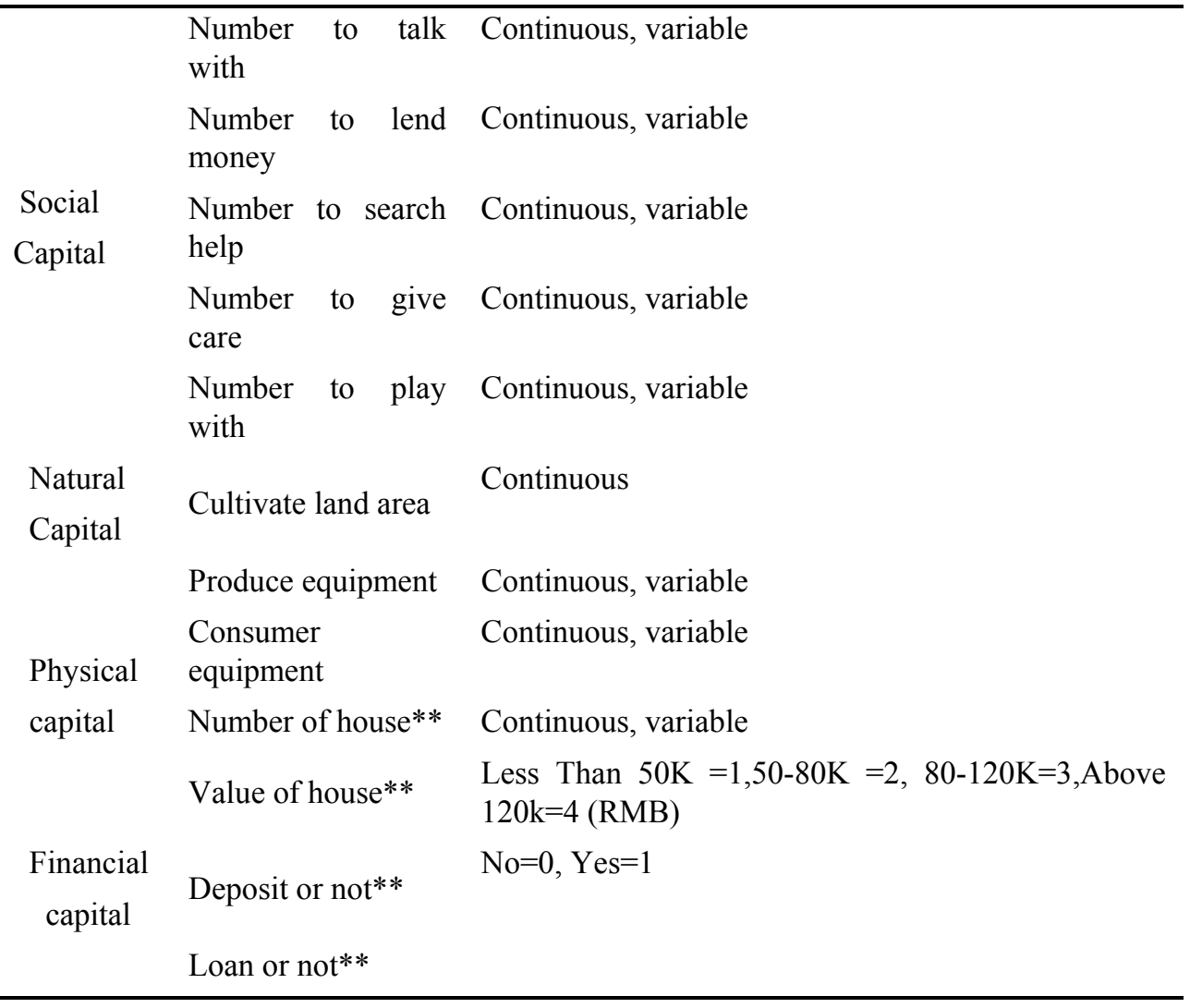

\subsection{Research Hypotheses}

Based on the previous analysis of the gap between the supply and demand of aged care, combined with the status of rural left-behind women(number of people, life, etc.), this paper proposes the following five aspects of the willingness of rural left-behind women to engage in aged are services.

Hypothesis 1: Human capital is positively related to the work of rural left-behind women in nursing care.

The Level of education in human capital, whether it has received skills training and work experience has shown positive effects. The higher the education level of rural left-behind women, the skill training, and the work experience of the second and third industries, it is easier to help the left-behind women to get out of the old generation, that is, the old concept that women should stay a t home to teach each other, and more help left-behind women to better complete work other than the primary industry. Therefore, it is assumed that human capital has a positive relationship with left-behind women who choose to engage in nursing care.

Hypothesis 2: Social capital is positively related to the work of rural left-behind women in nursing care.

The number of people who are in a bad mood in social capital, the number of people borrowing money when they are in urgent need, the number of people in need of production difficulties, the number of people who are sick and the number of people who are accommodating and relaxing, to some extent reflect the scale of social network support of left-behind women. Generally speaking, social scale women who are relatively large and able to get along with others are more positive and optimistic in their mentality. They are willing to accept new ideas and new working environment, and are more willing to pay and contribute. Therefore, social capital will also promote left-behind women to choose old-age care.

Hypothesis 3: Natural capital is negatively related to women's work in nursing care

Natural capital mainly includes arable land etc. Generally speaking, the more left-behind women who have the land capital, bear certain pressure on production and do not have spare time to do other work, the more land capital is owned, the more agriculture income is. Family economic decision-making will not allow left-behind women to do other work, so natural capital is considered to be a restraining effect.

Hypothesis4: Financial capital (deposits under the name) is negatively related to women's work in nursing care The more financial capital (the amount of deposits) owned by left-behind women, the less likely they are to 
engage in aged care work.

Hypothesis5: Material capital is negatively related to women's work in nursing care

The more production equipment and consumer equipment owned by left-behind women have brought convenience agricultural production to a certain extent, the lower the pressure on agricultural production for them. Then, the less likely they will engage in elderly care service, according to people's profit-seeking psychology

\section{Empirical Analysis}

\subsection{Sample Introduction and Data Source}

\subsubsection{Sample Introduction}

The city of Wugang is located in the southwest of Hunan province, with a total area of 1549 square kilometers and a total population of more than 800,000 . Of these, the urban area is 16.11 square kilometers and the permanent population is 26,000 . The city has four streets, eight towns and nine townships under its jurisdiction.

In the early 90's of the 20th century, the old male rural labor force in Wugang city began to flow to Shenzhen, Guangzhou and other economically developed cities. But under the pressure of high housing prices and inflation, almost all migrant workers are unable to transfer the whole family to the city. In this case, the phenomenon that the male labor force work outside the city and women are left behind in the hometown.

\subsubsection{Data Source}

The data source of this thesis mainly adopts random sampling method, in the village where the male labor force is more concentrated, 300 rural left-behind women were randomly selected as sample, the effective questionnaire was collected in 279 cases, and the effective rate was $93 \%$.

Table 2. Questionnaire recovery status table

\begin{tabular}{lcccc}
\hline Distribution & Release & Recovery & Effective & Recovery \\
Form & Q & Q & Q & rate \\
\hline Paper & 300 & 296 & 27 & $93 \%$ \\
\hline
\end{tabular}

\subsection{Data Analysis}

\subsubsection{Statistical Analysis of Data}

Effective questionnaires show that, the age distribution of left-behind women in rural areas is mainly between the ages of 31 and $50,23 \%$ are under $30,5 \%$ are over 50 , and $72 \%$ are between 31 and 50 .

\subsubsection{Statistical Inspection}

\section{(1) Reliability Test}

The research used Cronbach's Alpha and SPSS22.0 to carry on the data analysis, then the results showed that the coefficient of the total five scale was above which proved that the questionnaire had high reliability. (as shown in Table 3)

Table 3. Cronbach Alpha's results

\begin{tabular}{|c|c|}
\hline Scale & Cronbach's Alpha \\
\hline Human Capital & 0.741 \\
\hline Social Capital & 0.714 \\
\hline Natural Capital & 0.784 \\
\hline Physical Capital & 0.741 \\
\hline Financial Capital & 0.749 \\
\hline Total Amount & 0.746 \\
\hline
\end{tabular}


(2) Validity Test

In this paper, factor analysis is used to confirm the questionnaire's structural validity, the results shows that common factors existing in the mother group, which KMO value is 0.705 , the Bartlett value is 764.157 and the df value is 210. Meanwhile, the level of Sig. represents the good structural validity. (as shown in Table 4)

Table 4. KMO and Bartlett Value

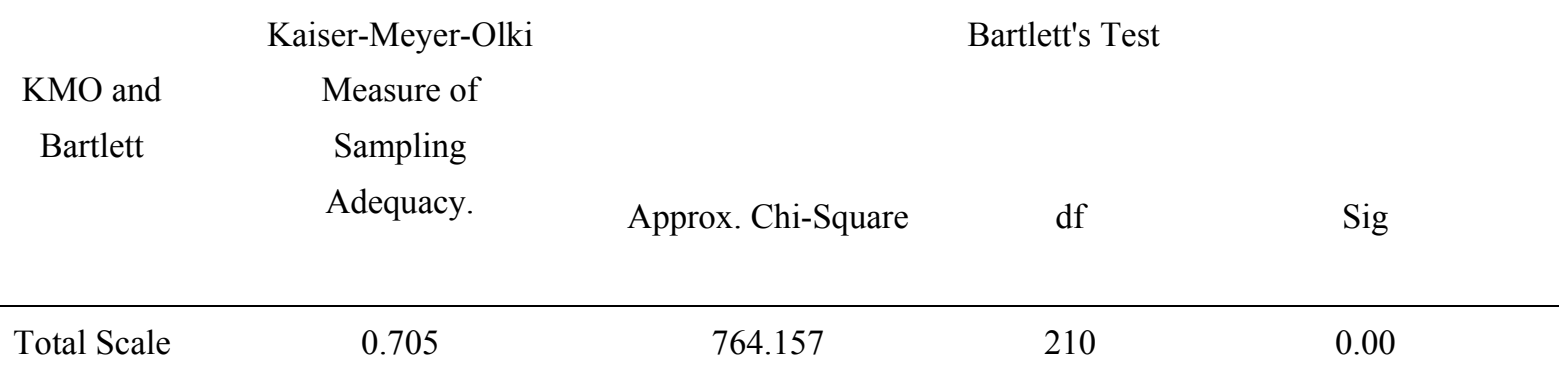

When examining the validity of the scale, the correlation coefficient between the factors can be considered. A good questionnaire structure requires that a correlation coefficient between factor and total scale is 0.3 to 0.8 , between factors is 0.1 to 0.6 . Table 5 shows that the correlation coefficient is consistent with the above conditions.

Table 5. The correlation coefficient

\begin{tabular}{llllllll}
\hline \multirow{5}{*}{ Correlation } & & HC & SC & NC & PC & FC & Total \\
& HC & 1.000 & & & & & \\
& SC & 0.276 & 1.000 & & & & \\
& NC & 0.197 & 0.12 & 1.000 & & & \\
& PC & 0.291 & 0.347 & 0.12 & 1.000 & & \\
& FC & 0.106 & 0.11 & 0.14 & 0.141 & 1.000 & \\
$\begin{array}{l}\text { Pearson } \\
\text { Coefficient }\end{array}$ & Total & 0.512 & 0.470 & 0.782 & 0.422 & 0.32 & 1.000 \\
\hline
\end{tabular}

\subsection{Results}

The result shows that the willingness of rural left-behind women to take up the elderly care service is relatively low. This paper uses SPSS and Logistic Regression Model to analyze the factors affecting the left behind women's willingness. Generally speaking, the model coefficient passes the overall test with the value of -2loglikelihood is 92.332, the Cox\& Snell R Square and the Nagelkerke R Square is 0.414 and 0.533 respectively. The followings are the hypotheses tests.

Table 6. Model results

\begin{tabular}{ccc}
\hline -2loglikelihood & Cox \&Snell R2 & Nagelkerke R 2 \\
\hline 92.332 & 0.414 & 0.533 \\
\hline
\end{tabular}


(1) The influence of human capital on the women's elderly care service.

The three factors affect the willingness $5 \%$ remarkably and positively, which is the cultural level, skill training experience, employment experience of second and third industries, and the index of health situation is not. It means that the higher cultural level and the richer experience the people have, the more accurate direction they choose.

(2) The influence of social capital on the women's elderly care service.

All the variables of social capital did not pass the significance test. This is not consistent with the assumption. The possible reason is that the left behind women have no worries about the social network cause of their getting along well with the neighbor.

(3) The influence of natural capital on the women's elderly care service.

The cultivated land area is not significant to affect the willingness, which is consistent with the before research. The possible reason is the family's income and leisure time is not related to the land area.

(4) The influence of physical capital on the women's elderly care service.

The two variables that the number and the value of houses are significant, but they are the different direction, that means the lower the house value the more likely left behind women to take up, the more houses the more unlikely. It is to say that the physical capital inhibit the will, which is consistent with the assumption.

(5) The influence of financial capital on the women's elderly care service.

The two variables having deposit and gain loan or not are significant financial factors in the test. That means the more stable income and deposit the left behind women have, the more likely willing they take up, and it is the opposite when they have loans because the present salary level is too low to pay back their loans.

Table 7. Regression results

\begin{tabular}{|c|c|c|c|c|c|c|}
\hline & \multirow{2}{*}{ Variable } & \multicolumn{5}{|c|}{ Left behind women } \\
\hline & & B & S.E & Wals & Sig & $\operatorname{Exp}(\mathrm{B})$ \\
\hline \multirow{4}{*}{$\begin{array}{l}\text { Human } \\
\text { Capital }\end{array}$} & Education level** & 1.336 & 0.403 & 11.001 & 0.001 & 0.263 \\
\hline & skill or not $* *$ & 1.599 & 0.785 & 4.154 & 0.042 & 4.95 \\
\hline & Employment experience** & 2.192 & 0.881 & 6.189 & 0.013 & 8.957 \\
\hline & Health situation & -0.03 & 0.371 & 0.006 & 0.936 & 0.971 \\
\hline \multirow{5}{*}{$\begin{array}{l}\text { Social } \\
\text { Capital }\end{array}$} & Number to talk with & 0.107 & 0.351 & 0.093 & 0.76 & 1.113 \\
\hline & Number to lend money & 0.384 & 0.455 & 0.712 & 0.399 & 1.468 \\
\hline & Number to search help & -0.707 & 0.479 & 2.178 & 0.14 & 0.493 \\
\hline & Number to give care & -0.197 & 0.468 & 0.117 & 0.674 & 0.821 \\
\hline & Number to play with & 0.401 & 0.548 & 0.535 & 0.464 & 1.493 \\
\hline \multirow[t]{2}{*}{$\begin{array}{l}\text { Natural } \\
\text { Capital }\end{array}$} & Cultivate land area & -0.346 & 0.218 & 2.515 & 0.113 & 0.708 \\
\hline & Produce equipment & 1.103 & 1.017 & 1.176 & 0.278 & 3.013 \\
\hline \multirow{3}{*}{$\begin{array}{c}\text { Physical } \\
\text { Capital }\end{array}$} & Consumer equipment & -0.29 & 1.108 & 0.068 & 0.794 & 0.748 \\
\hline & Number of house ${ }^{* *}$ & -1.014 & 0.526 & 3.712 & 0.054 & 2.756 \\
\hline & Value of house** & -1.112 & 0.403 & 7.632 & 0.006 & 0.329 \\
\hline \multirow{2}{*}{ Financial } & Deposit or not** & 2.88 & 0.974 & 8.747 & 0.003 & 17.81 \\
\hline & Loan or not** & -2.109 & 0.88 & 5.745 & 0.017 & 0.121 \\
\hline
\end{tabular}

Note: $* * 5 \%$ significance 


\section{Conclusions and Suggestions}

\subsection{Conclusions}

Using the logistic regression analysis, the main conclusions are:

(1) That three factors of the cultural level, skill training experience, employment experience of second and third industries affect the willingness $5 \%$ remarkably and positively.

(2) The effect of the social capital and natural capital is not significant.

(3) The physical capital are significant, It is to say that the physical capital inhibit the will, which is consistent with the assumption.

(4) The two variables having deposit and gain loan or not are significant financial factors in the test.

\subsection{Suggestions}

(1) Play the government's main role to build the re-education system.

From both theoretical and practical point of view, human capital is the fundamental factor in determining survival. Education level affect the left behind women's being elderly care willingness positively. So the government should set up a special fund to invest in the education and training for the rural left behind women, actively encourage all sectors of society to increase spending on education and create a favorable economic environment. Meanwhile, in the view of the different characteristics of the left behind women, the government should establish an effective hierarchical education and training mechanism to create a good cultural environment. For example, to held the cooking, medical care skill training.

(2) Develop people's livelihood finance and provide assistance to rural left behind women.

It is found that the stability of financial capital plays a positive role in the elderly care for the rural left behind women. In order to improve their financial capacity, there are three methods. First, design a financial product according to their demands. Most of the left behind women have low income, poor skill resistance and professional financial management skills, therefore, financial institutions should design and launch the financial instruments and products supporting demands and social security. Second, implement the insurance guarantee system. The main reason why the rural people's livelihood finance is not active is that the credit mechanism has not been established. So the state should introduce the insurance guarantee system as soon as possible so as to spread and share the investment risk.

(3) Strengthen the government's attention and perfect the policy and regulations of elderly care service.

In the research, which the views of the elderly care service is also an important factor affecting their willingness. Therefore, the government should actively promote the elderly care service, the grassroots organizations should popularize the importance and the basic knowledge of elderly care service, carry out nursing skill training. Once the elderly care has become a social undertaking, the left behind women will participate it actively.

\section{References}

Chen, F. (2014). Family life satisfaction and its influencing factors of rural left-behind women-based on 964 survey data from Hunan province. Journal of Hunan Agricultural University (Social Science Edition).

$\mathrm{Hu}, \mathrm{Y}$. (2011). The dilemma and the choice of employment for the left-behind women in northwest rural areas from the perspective of the internal division of labor within the family-taking Anhui province as an example. Anhui Journal of Agriculture Science, (3).

Liu, W., \& Wang, M. (2009). Analysis on the problem of rural left-behind women from the perspective of new countryside. Economic Research Guide, (4).

Luo, C. (2015). Impact of livelihood capital on the willingness of rural left-behind women to go out to work-taking Chaohu lake, Anhui province as an example. Northwest Population Journal, (3).

Wu, H., \& Rao, J. (2010). Analysis on the social network reconstruction of rural left-behind women. Journal of Rural Observation in China, 4.

$\mathrm{Wu}$, Y. (2013). Report on the development of China's aging industry. Beijing: Social Science Literature Publishing House.

Zhao, X. (2011). Impact of livelihood capital on life satisfaction of farmers and herdsmen-taking Gannan plateau as an example. Journal of Geographical Research, 4. 


\section{Copyrights}

Copyright for this article is retained by the author(s), with first publication rights granted to the journal.

This is an open-access article distributed under the terms and conditions of the Creative Commons Attribution license (http://creativecommons.org/licenses/by/4.0/). 